\title{
Roles of the androgen receptor cofactor p44 in the growth of prostate epithelial cells
}

\author{
Liran Zhou*, Hong Wu*, Peng Lee ${ }^{1}$ and Zhengxin Wang \\ Department of Cancer Biology, The University of Texas MD Anderson Cancer Center, 1515 Holcombe Boulevard-173, Houston, Texas 77030, USA \\ ${ }^{1}$ Department of Pathology, New York University School of Medicine, New York, New York 10010, USA \\ (Requests for offprints should be addressed to Z Wang; Email: zhenwang @mdanderson.org) \\ *( L Zhou and H Wu contributed equally to this work)
}

\begin{abstract}
Various cofactors have been shown to regulate androgen receptor (AR) transactivation, but their physiological functions in the AR pathway and prostate tumorigenesis are undefined. Here, we found that AR cofactor (p44) translocation from the nucleus to the cytoplasm in prostate epithelial cells (ECs) is associated with prostate tumorigenesis. The forced nuclear localization of p44 inhibited prostate cancer cell growth by G1 cell-cycle arrest. Consistently, mice lacking one allele of the p44 gene developed prostatic hyperplasia. Therefore, p44 is required for proper expression of AR-target genes to maintain the differentiation of prostate ECs, and p44 translocation from the nucleus into the cytoplasm in prostate cancer cells or loss of one allele in mouse results in excessive prostate EC proliferation.
\end{abstract}

Journal of Molecular Endocrinology (2006) 37, 283-300

\section{Introduction}

The functional androgen-signaling pathway is essential for the development and maintenance of normal prostate glands (Kokontis \& Liao 1999). The present model of androgen functions in the prostate gland is that androgens increase the proliferation of prostate cells and androgen withdrawal has the potential to inhibit prostate cell growth and induce apoptosis (Lindzey et al. 1994, Jenster 1999). This model mainly results from the observation that reducing androgen levels by castration leads to rapid shrinkage of the prostate gland, primarily because of luminal cell apoptosis (Denmeade et al. 1996). However, many examples can be found in which the androgensignaling pathway can actually inhibit the growth of prostatic cells (Tilley et al. 1990, Yuan et al. 1993, Lee et al. 1995, Nelson et al. 2000, Xu et al. 2001, Whitacre et al. 2002). The androgen-mediated growth inhibition of these cells results from androgen-induced terminal cell differentiation (Whitacre et al. 2002). The ability of androgens to mediate growth suppression reflects the dual role of androgens in first inducing the proliferation of cells toward growth of the prostate and then in maintaining the differentiated state of the prostatic cells in the mature gland (Mirosevich et al. 1999). There is increasing evidence that the androgen-signaling pathway is involved in many phases of prostate cancer biology, including tumorigenesis, disease progression, and the development of resistance to anti-androgen therapies (Buchanan et al. 2001, Huang \& Tindall 2002, Dehm \& Tindall 2005). However, the molecular mechanisms of the androgen-signaling pathway involved in these processes are still unknown. Given the importance of the androgen-signaling pathway in prostatic homeostasis as well as in prostate cancer, considerable efforts have been directed at revealing the mechanisms of androgen action.

The androgen receptor (AR) is a ligand-activated transcription factor that regulates the expression of target genes to mediate the biological function of androgens (Brinkmann et al. 1999, He \& Wilson 2002). The binding of androgen to AR induces a cascade of events that lead to AR activation. These processes include the dissociation of AR from heat shock proteins, the formation of receptor homodimerization, and the recruitment of $\mathrm{AR}$ to androgen response elements located within AR-target genes. Once activated by a ligand, AR interacts with various cofactors that facilitate transcription by the general transcriptional machinery (Janne et al. 2000, Gelmann 2002, Heinlein \& Chang 2002). Several classes of AR cofactors possess histone acetyltransferase or histone methyltransferase activities and are thought to act mainly by producing histone acetylation or methylation and consequent chromatin structural perturbations. Many other AR cofactors have been identified, but the mechanisms of their actions are less well described (ww2.mcgill.ca/androgendb/ARinteract.pdf). We and other researchers have observed increased expression 
of some cofactors and decreased expression of others in prostate tumor tissue compared with the adjacent benign prostate tissue, indicating that cofactors may play important roles in prostate tumorigenesis and cancer progression (Nessler-Menardi et al. 2000, Li et al. 2002, Culig et al. 2004). Although increasing numbers of AR cofactors have been identified, their biological relevance to the prostate gland, as well as to prostate cancer growth and progression remains to be tested in vivo in knockout and transgenic mice.

In a previous study, we identified a novel $44 \mathrm{kDa}$ protein, designated $\mathrm{p} 44$, as an AR-interacting protein capable of influencing AR-transcriptional activity (Hosohata et al. 2003). The human p44 protein contains 342 amino acid residues and four putative WD-40 repeats (residues 68-107, 114-153, 157-196, and 280-319) and is identical in sequence to the MEP50 component of the methylosome (Friesen et al. 2002) and the WD45 subunit of the survival motor neuron (SMN)-complex (Meister \& Fischer 2002). The methylosome complex contains protein arginine methyltransferase-5/Janus-2 binding protein 1 (PRMT5 $/ \mathrm{JBP} 1$ ), $\mathrm{Cl}^{-}$channel-associated protein ( $\mathrm{pICln}$ ), and Sm proteins and mediates the assembly of spliceosomal small nuclear ribonucleoprotein. (snRNP) (Friesen et al. 2001). The p44 protein may form distinct complexes with different proteins in the cytoplasm and the nucleus for different roles (transcription versus splicing). Northern blot analysis of multiple human tissues showed that p44 mRNA is highly expressed in the heart, skeletal muscle, spleen, testis, uterus, prostate, and thymus (Hosohata et al. 2003). Here, we demonstrated that p44 plays important roles in the proper expression of AR-target genes to maintain the differentiation stage of prostate epithelial cells (ECs) in the prostate gland. p44 translocation from the nucleus into the cytoplasm in prostate cancer cells or the loss of one allele in mouse prostate glands results in excessive EC proliferation.

\section{Materials and methods}

\section{Immunohistochemistry staining}

Prostate cancerous and normal prostate tissues were derived from radical prostatectomy specimens of 44 patients with prostate cancer treated at New York University Medical Center, and the study protocol was approved by its institutional review board. The histological features of each specimen were confirmed by the pathologist (Dr Peng Lee). The tissues were fixed in $10 \%$ neutral buffered formalin and embedded in paraffin. We validated specimen by immunohistochemical and in situ hybridization analyses for expressions of AR and prostate-specific antigen (PSA), which are highly expressed in the prostate gland. If the protein and mRNA signals of AR and PSA were evident, the specimens were chosen for immunohistochemical analysis of the p44 protein. lymph node carcinoma of prostate (LNCaP) stable cell lines were grown on poly-lysine-coated cover glasses overnight, fixed in $3.7 \%$ paraformaldehyde, and immunostained with anti-AR or anti-p44 antibodies. To make cell blocks, cells of LNCaP stable cell lines were fixed in 3\% paraformaldehyde and embedded in $0.9 \%$ agar and then in paraffin. Four micrometer sections of prostate tissues and LNCaP cell blocks were cut and mounted on Super-frost Plus adhesion slides (Fisher, Pittsburgh, PA, USA) and immunohistochemical analysis was performed. Anti-keratin 18 (K18; 1:50) and anti-keratin $5(\mathrm{~K} 5 ; 1: 1000)$ were purchased from CHEMICON International (Temecula, CA, USA). The antigen-purified anti-p44 (1:100) and anti-AR (1:200) antibodies were described previously (Yu et al. 2001, Hosohata et al. 2003). Antibodies were applied to the prostate or LNCaP cell sections and incubated overnight. A streptavidin-biotin peroxidase detection system (for prostate tissues) with 3,3'-diaminobenzidine as substrate was used according to the manufacturer's instructions (DAKO A/S, Grostrup, Denmark).

\section{Establishment of the stable prostate cancer cell lines}

The FLAG epitope tag (DYKLDDDDK) or the FLAG epitope plus a strong nuclear localization signal (NLS; PKKKRKV) was fused at the N-terminal end of p44 and subcloned into pcDNA3 1 to generate f:p44 or f:NLSp44 plasmid. LNCaP cells were transfected with $1 \mu \mathrm{g}$ pcDNA, f:p44, or f:NLS-p44 and selected with G418 $(0.5 \mathrm{mg} / \mathrm{ml})$. The medium was changed every 3 or 4 days. Individual G418-resistant colonies were expanded into cell lines and then characterized by western blotting using the anti-FLAG monoclonal antibody M2 (Sigma). The cDNAs encoding the NLSp44 and p44 were subcloned into pEGFP-C1 to generate pEGFP-p44 and pEGFP-NLS-p44. The stable LNCaP cells expressing EGFP-p44 and EGFP-NLS-p44 were established similarly.

\section{Cell proliferation assays}

The stable LNCaP cell lines were cultured in 24-well plates at a density of $5 \times 10^{3}$ per well and grown in RPMI1640 medium (Invitrogen) supplemented with $10 \%$ fetal bovine serum. Cell numbers were counted in triplicate every day. The cell proliferation index (Ki67) was determined following the standard immunostaining procedure with 1:25 diluted Ki67 MIB-1 antibody (DAKO A/S). 


\section{Transient transfection, northern, and western blot assays}

The LNCaP or PC3 cells were maintained in RPMI-1640 medium plus $10 \%$ fetal bovine serum. A transient transfection assay was performed with the Lipofectamine Transfection Reagent (Invitrogen) as described (Hosohata et al. 2003). Briefly, the PC3 cells were transfected with $100 \mathrm{ng}$ luciferase reporter (PGL3-p21), 2.5 ng pRL-CMV, 10 ng pcDNA-f:AR, and 150 ng pcDNAf:p44. The transfected PC3 cells were grown in the absence or presence of $10 \mathrm{nM} \mathrm{R} 1881$ for $48 \mathrm{~h}$ and then harvested for the Dual-Luciferase Reporter Assay (Promega).

Northern blot analysis was performed as described previously (Gao et al. 2005). Briefly, LNCaP cells were grown in the absence or presence of $10 \mathrm{nM} \mathrm{R} 1881$ for 2 days. The mRNAs were isolated from cells, fractionated by electrophoresis, and transferred to a Hybond $\mathrm{N}^{+}$membrane (Amersham Biosciences). The membrane was hybridized with cDNA probes of the p21, p27, CDK2, CDK4, or $\beta$-actin genes.

In a western blot assay, the whole-cell lysates $(15 \mu \mathrm{g})$ were separated by $12 \%$ SDS-PAGE and proteins were transferred to the $0.45 \mu \mathrm{m}$ Protran Nitrocellulose membrane (Whatman, Inc., Florham Park, NJ, USA). The membrane was blocked for $30 \mathrm{~min}$ in $3 \%$ nonfat dry milk in tris buffered saline tween-20 (TBST) (20 mM Tris-HCl (pH 7.6), $150 \mathrm{mM} \mathrm{NaCl}$, and $0 \cdot 1 \%$ Tween 20 ). The blot was incubated with anti-p44 (1:5000), anti-p21 (1:1000; Upstate USA, Inc., Charlottesville, VA, USA), or anti-actin (1:1000; Sigma) antibody for $2 \mathrm{~h}$ at room temperature, washed with TBST three times, and incubated for $1.5 \mathrm{~h}$ with the second antibody (1:5000; Amersham Biosciences). Antibodies were diluted with $2 \%$ BSA in TBST. The protein bands were detected by an enhanced chemiluminescence kit (Amersham Biosciences).

\section{DNA microarray and real time-PCR}

Total RNAs were isolated from f:NLS-p44 and f:p44 LNCaP cell lines by using the RNeasy Protect Mini Kit (Qiagen, Inc.). The Human Genome U133plus2.0 arrays were purchased from Affymetrix (Santa Clara, CA, USA) and microarray analysis was performed by the Murine Microarray and Affimetrix Facility at MD Anderson Cancer Center (Cancer Center Support Grant CA16672). Array signals were harvested by the GeneArray Scanner (Affimetrix) and were processed by the Microarray Suite software (Affimetrix).

The total RNAs were reverse transcribed by using the Reaction Ready First Strand cDNA Synthesis Kit (SupperArray Bioscience Corp., Fredrick, MD, USA). The resulting cDNA products were PCR-amplified (40 cycles of $30 \mathrm{~s}$ at $94^{\circ} \mathrm{C}$; $20 \mathrm{~s}$ at $55^{\circ} \mathrm{C}$; and $30 \mathrm{~s}$ at $72^{\circ} \mathrm{C}$ ) with the $\mathrm{RT}^{2}$ real-time SyBRgreen PCR master mix and the genespecific primer set by the SmartCycler II (Cepheid,
Sunnyvale, CA, USA). The raw data procession and quantification were performed with the SmartCycler Software (Cepheid; version 2.0C). Reverse transcriptase (RT)-PCR primer sets for human: PSA (PPH01002A), prostate-derived Ets factor (PDEF) (PPH02282A), Maspin (PPH00695A), insulin-like growth factor-binding protein-5 (PPH00312A), and $\beta$-actin (PPH00073A) and for mouse: neutral endopeptidase (NEP) (PPM03215A), PDEF (PPM05224A), NKX3·1 (PPM05232A), cyclin-dependent kinase-2 (CDK2) (PPM02902A), Maspin (PPM03665A), transforming growth factor- $\beta 1$ (PPM02991A), and $\beta$-actin (PPM02945A) were purchased from SupperArray Bioscience Corp.

\section{Chromatin immunoprecipitation}

Chromatin immunoprecipitation (CHIP) was performed as described previously (Gao et al. 2005). Briefly, LNCaP cells were grown in the absence or presence of $10 \mathrm{nM} \mathrm{R} 1881$ and cross-linked with $10 \%$ formalin for $10 \mathrm{~min}$ at room temperature. The DNAprotein complexes were purified with antigen-purified anti-AR or anti-p44 antibody. The purified DNA was amplified by a PCR with two specific primers derived from promoter regions of $\beta$-actin ( -71 to $-215 \mathrm{bp}$ ) or p21 ( -193 to $-215 \mathrm{bp})$. The same set of PCRs was performed with the chromatin DNA used for CHIP.

\section{Generation of the p44 knockout mice}

To isolate the mouse $p 44$ gene, a mouse 129SvJ genomic library (Stratagene, La Jolla, CA, USA) was screened with a mouse $p 44 \mathrm{cDNA}$ probe. Ten overlapping clones contained ten exons of the $p 44$ gene locus. The genomic fragment containing parts of exon 1 and exons 2-4 was replaced by a phosphoglycerate kinase neo-cassette (Fig. 5A). This replacement ablated the $\mathrm{NH}_{2}$-terminal portion (amino acid residues 1-154) of $\mathrm{p} 44$. The targeting vector included a $5 \cdot 0 \mathrm{~kb}$ upstream homologous region and a $4.6 \mathrm{~kb}$ downstream region. The embryonic stem (ES) electroporation and blastocyst injection were performed by the Genetically Engineered Mouse Facility at MD Anderson Cancer Center. Briefly, E14 ES cells were electroporated with the linearized targeting vector and selected with geneticin on embryonic fibroblast feeder cells. In total, 348 G418-resistant clones were screened by Southern blot analysis using the $3^{\prime}$ external probe; 12 clones displayed evidence of homologous recombination of the disrupted $p 44$ gene. Two ES clones were microinjected into the blastocysts of C57BL6/J female mice. Germline chimeras were bred to C57BL6/J mice to generate heterozygous mutant $\mathrm{F} 1$ mice. All the animal experiments were performed according to the protocol approved by the Institutional Animal Care and Use 
Committee at the University of Texas, MD Anderson Cancer Center. For genotyping, the genomic DNA isolated from ES cells or mouse tails was subjected to Southern blot analysis with a $3^{\prime}$ external probe or used for PCR analysis (primer sequences are available on request). Northern blot analysis was performed with the full-length p44 cDNA as a probe. For the histology, the prostate glands were dissected and fixed with $10 \%$ buffered-formalin and embedded in paraffin blocks. Four-micrometer tissue sections were deparaffinized, rehydrated, and stained with hematoxylin and eosin.

\section{Castration-induced apoptosis in the prostate gland}

Wild-type and $p 44^{+/-}$male mice were castrated at 8 weeks of age under anesthesia in accordance with the protocol approved by the International Animal Care and Use Committee. At 30 days after the operation, the mice were treated hormonally by surgical implantation of a $2 \mathrm{~cm}$ Silastic capsule filled with $25 \mathrm{mg}$ testosterone (Sigma) for 2 months. The Silastic tubing (Fisher Scientific, Hampton, NH, USA) had an inside diameter of $1.54 \mathrm{~mm}$ and an outside diameter of $3.18 \mathrm{~mm}$. The control group received empty Silastic capsules. The mice prostate glands were dissected 60 days after testosterone replacement, fixed in $10 \%$ formalin overnight, and embedded in paraffin. The paraffinembedded sections ( $4 \mu \mathrm{m}$ thick) were cut and mounted on glass slides. After being de-waxed, the paraffinembedded sections were stained with hematoxylin and eosin or used for immunohistochemical staining.

\section{Results}

\section{p44 translocated from the nucleus to the cytoplasm in prostate cancer}

We previously demonstrated significant $\mathrm{p} 44$ upregulation at mRNA levels in prostate cancer cells compared with adjacent benign prostatic epithelium by in situ hybridization (Hosohata et al. 2003). These results implied that the abnormal expression of p44 might play an important role in prostate tumorigenesis. To further explore the roles of p44 in prostate cancer, we used immunohistochemical analysis with an antigen-purified anti-p44 polyclonal antibody to investigate $\mathrm{p} 44$ protein expression. Matched prostate cancerous and benign prostate tissues were derived from 44 patients with prostate cancer. The p44 immunostaining signal was strong in the nuclei (indicated by the red arrowhead) of ECs in the benign areas, but absent in the stroma cells (Fig. 1A). In contrast, in the prostatic intraepithelial neoplasia (PIN) and tumor areas (43 of 44 cases), the nuclear staining was significantly decreased and strong immunostaining of p44 was observed mainly in the cytoplasm (indicated by the white arrowheads) of ECs (Fig. $1 \mathrm{~B}$ and C). As indicated by the red circle in Fig. 1B, the p44 translocation from the nucleus (indicated by the red arrowheads) to the cytoplasm (indicated by the white arrowheads) occurred, when EC cells grew from single layer in benign epithelium to multiple layers in PIN. Although the p44 mRNA levels were increased in the prostate tumors (Hosohata et al. 2003), changes in the subcellular localization decrease the levels of the p44 protein in the nucleus of prostate cancer cells and may signify the proliferation of ECs. Immunohistochemical staining with anti-p44 antibody revealed that p44 localizes mainly in the cytoplasm of prostate cancer LNCaP cells (Fig. 1D-F). The immunostaining signals were suppressed by the recombinant $\mathrm{p} 44$ and the similar subcellular localization of the enhanced green fluorescent protein (EGFP-p44) fusion protein were observed in LNCaP cells (Fig. 1G), indicating the specificity of the signals obtained by the immunohistochemical analysis.

To investigate whether $\mathrm{p} 44$ co-localizes with $\mathrm{AR}$ and the p44 subcellular localization would affect the androgen-driven AR nuclear localization, we grew the LNCaP cell lines stably expressing the EGFP-p44 or EGFP-NLS-p44 fusion proteins in the presence or absence of the androgen (R1881). Cells were fixed and immunostained with anti-AR antibody. AR was diffused in the whole cell in the absence of the androgen (Fig. $1 \mathrm{H}, \mathrm{N}$ ) and localized mainly in the nucleus in the presence of the androgen $(\mathrm{K}, \mathrm{Q})$. The $\mathrm{p} 44$ co-localized with AR in the cytoplasm of EGFP-p44 cell line in the absence of the androgen (Fig. 1G-I) and in the nucleus of EGFP-NLS-p44 cell line in the presence of the androgen (P-R). The p44 did not affect the androgendriven $\mathrm{AR}$ nuclear localization $(\mathrm{H}$ vs $\mathrm{K}, \mathrm{N}$ vs $\mathrm{Q})$; no matter it localized in the cytoplasm ( $\mathrm{H}$ vs $\mathrm{K}$ ) or nucleus ( $\mathrm{N}$ vs $\mathrm{Q}$ ). Consistent with these observations, we found that AR always localized in the nucleus of benign and tumor ECs (Li et al. 2002), even though p44 translocated from the nucleus into the cytoplasm.

\section{The forced nuclear localization of p44 inhibited proliferation of prostate cancer cells}

To establish the function of p44 in the nucleus, we forced the translocation of p44 into the nucleus of LNCaP cells by fusing a strong NLS (Jans et al. 2000) at the N-terminal end of $\mathrm{p} 44$. The stable LNCaP cell lines expressing the FLAG epitope-tagged NLS-p44 (f:NLSp44) or p44 (f:p44) were established. Western blot analysis with the monoclonal anti-FLAG antibody revealed that these cell lines expressed various levels of the f:NLS-p44 or f:p44 (Fig. 2A, inserts). The cytoplasm localization of p44 (Fig. 2A-C) and f:p44 (Fig. 2G-I) and the forced nuclear localization of f:NLS-p44 (Fig. 2D-F, indicated by the white arrows) were clearly demonstrated by immunohistochemical 

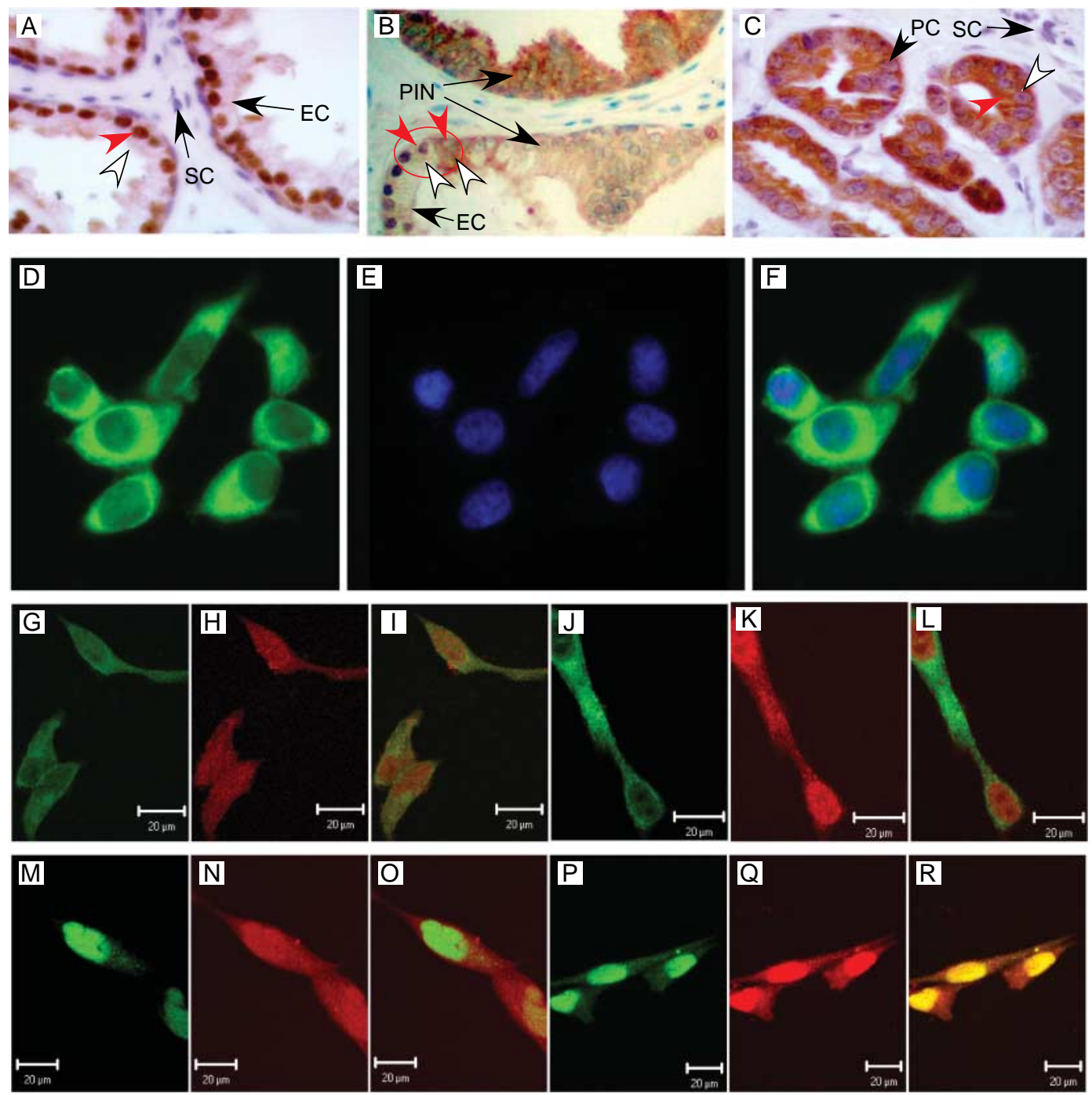

Figure 1 The distinct subcellular localization of p44 in benign and malignant prostate tissues. Immunohistochemical staining of p44 in (A) human benign, (B) prostatic epithelial hyperplasia (PIN), and (C) malignant prostate tissues. (D) Subcellular localization of p44 in LNCaP cells. LNCaP cells were immunohistochemically stained with anti-p44 antibody and the fluorescein isothiocyanate-labeled anti-rabbit immunoglobulin $\mathrm{G}$ antibody. The fluorescent signals were observed under a cofocal microscope. (E) DAPI staining of the nucleus of LNCaP cell. (F) Merge of D with $E$. EC, epithelial cell; SC, stroma cell. The nucleus and the cytoplasm of prostatic epithelial $(A, B$, and $C)$ cells are indicated by the red and white arrowheads respectively. The EGFP-p44 (G-L) and EGFP-NLS-p44 (M-R) LNCaP cell lines were grown in the absence $(G-I$ and $M-O)$ or presence $(J-L$ and $P-R)$ of $10 \mathrm{nM} R 1881$. Cells were immunohistochemically stained with anti-AR antibody and the Alexa-labeled anti-rabbit immunoglobulin $\mathrm{G}$ antibody. The fluorescent signals were observed under a cofocal microscope with a green (to detect the EGFP fusion proteins, $G, J, M$, and $P$ ) or red (to detect the AR protein, $H, K, N$, and $Q$ ) filter. I, L, O, and R are merges of $G$ with $H$, $\mathrm{J}$ with $\mathrm{K}, \mathrm{M}$ with $\mathrm{N}$, and $\mathrm{P}$ with $\mathrm{Q}$ respectively.

staining with the anti-p44 antibody in all cell lines. We chose two lines (with medium and high expression levels of the FLAG epitope-tagged NLS-p44 or p44) from each group for further analysis. Levels of the FLAG epitope-tagged proteins in the cell lines \#17 and \#4 were comparable to levels of the endogenous (nontagged) p44 protein (data not shown). The doubling time of the vector-transfected cells (V) was $36 \mathrm{~h}$, which was similar to that of the parental LNCaP cells. The doubling time for f:NLS-p44 stably expressing cell lines \#6 and \#17 were 41 and $56 \mathrm{~h}$ respectively. These results indicated that f:NLS-p44 expression (stable) inhibited the growth of LNCaP cells in a dosagedependent manner (Fig. 2A, left panel). In contrast, 
A
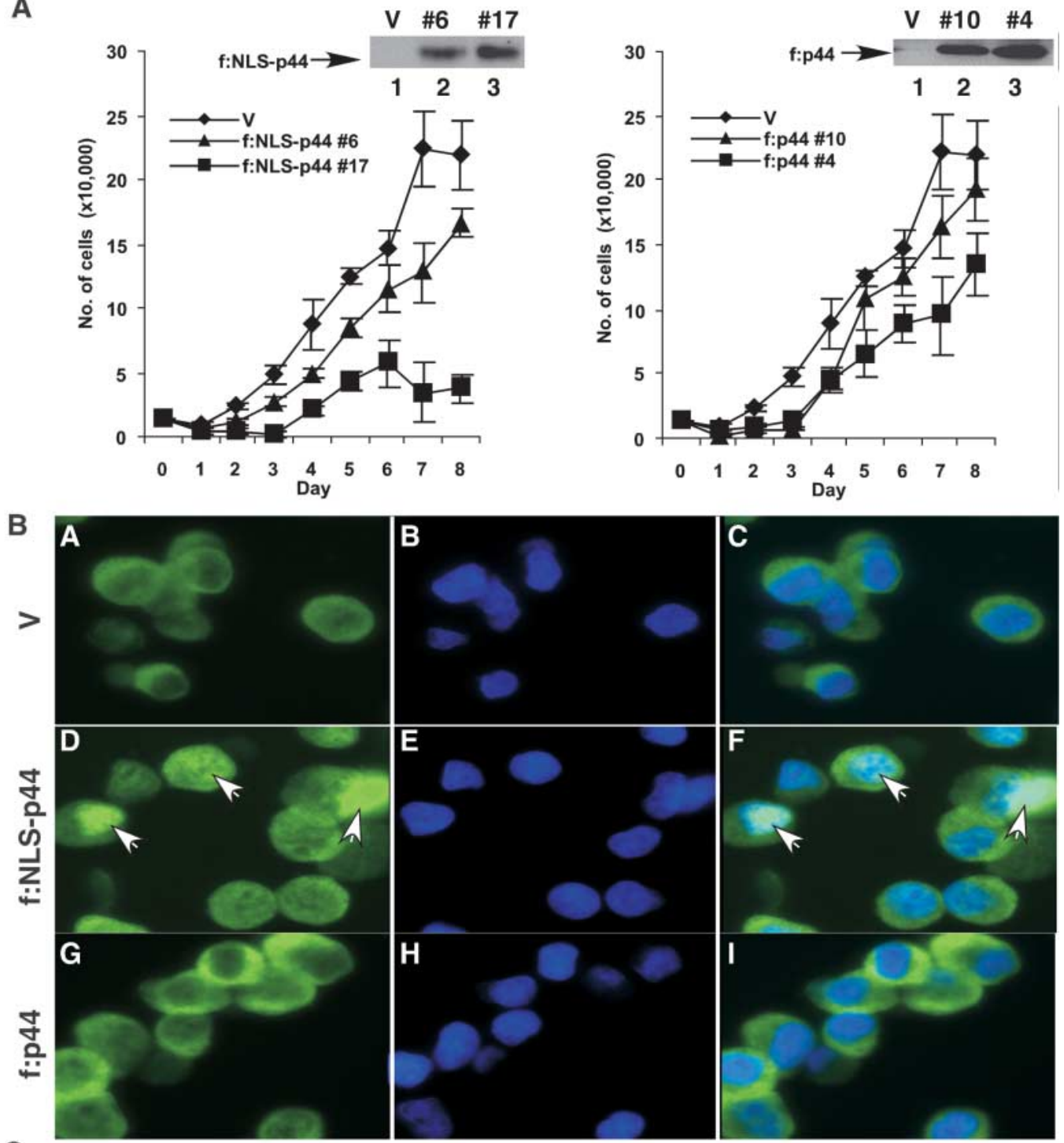

C

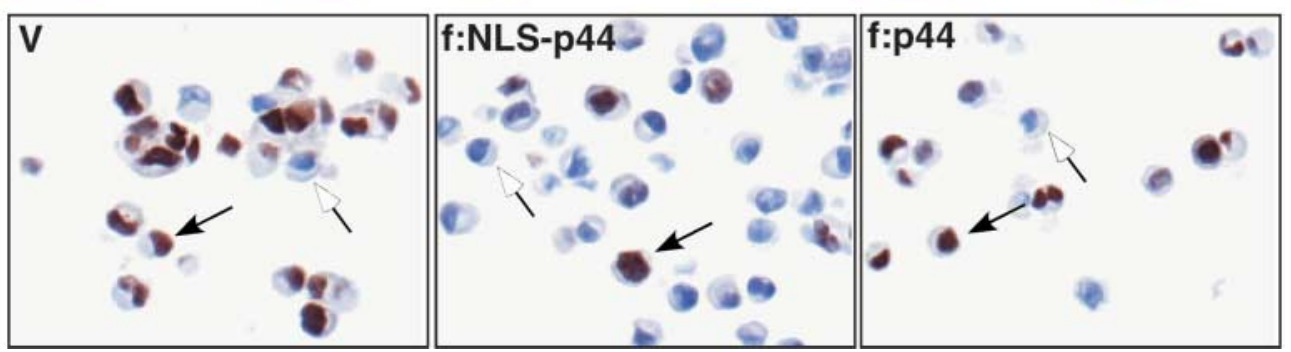

Figure 2 The forced nuclear localization of $p 44$ inhibits the growth of prostate cancer cells. (A) The growth curves of the stable LNCaP cell lines. Inserts, western blot analysis of the stable LNCaP cell lines transfected with the vector (V), f:NLS-p44 (left panel), or f:p44 (right panel). (B) Immunohistochemical staining of the stable LNCaP cell lines with anti-p44 antibody and the fluorescein isothiocyanate-labeled anti-rabbit immunoglobulin $G$ antibody (A, D, and G). B, E, H and C, F, I show DAPI staining of the nucleus and the merge of immunostaining with DAPI staining respectively. (C) Ki67 staining of the stable LNCaP cell lines. Cells lacking Ki67 are blue (indicated by white arrows), and those that have Ki67 are brown (indicated by black arrows). 
the growth rate of the f:p44 stably transfected LNCaP cells (cell lines \#10 and \#4; p44 localized mainly in the cytoplasm) was only slightly slower than that of the vector-transfected LNCaP cells (Fig. 2A, right panel), indicating that the nuclear localization of p44 was essential for the observed growth inhibition of LNCaP cells.

\section{The subcellular translocation of p44 altered cell-cycle progression}

We then evaluated the effect of f:NLS-p44 expression on apoptosis in LNCaP cells by using the in situ terminal deoxynucleotide transferase-mediated nick end labeling method. A few $(<0 \cdot 1 \%)$ f:NLS-p44-expressing cells underwent apoptosis, but no difference in the degree of apoptosis was found between the vector-transfected control cells and the f:NLS-p44-expressing cells (data not shown). Similarly, the transient transfection of pcDNA-f:p44 or pcDNA-f:NLS-p44 did not significantly $(<1 \%)$ induce apoptosis in LNCaP cells (data not shown). This observation indicated that f:NLS-p44 expression did not induce apoptosis in LNCaP cells. The proliferation of LNCaP cells was measured by immunohistochemical staining with anti-Ki67 monoclonal antibody. We observed high percentages $(82 \%)$ of Ki67-positive cells in the control LNCaP cells (V), but a reduced percentage $(15 \%)$ in f:NLS-p44-expressing LNCaP cells (f:NLS-p44; Fig. 2C). Taken together, these results indicate that f:NLS-p44 expression inhibited the growth of LNCaP cells through alterations in proliferation. We next determined whether the nuclear localization of p44 affected the cell-cycle progression. Flow cytometry analysis showed a substantial increase in the ratio of $\mathrm{G} 1$ to $\mathrm{S} / \mathrm{G} 2 / \mathrm{M}$ cells, from $1 \cdot 1$ to $2 \cdot 0$ in f:NLS-p44-expressing LNCaP cells, compared with the control LNCaP cells (data not shown). Thus, the slow growth rate of the f:NLS-p44-expressing cells can be attributed to the arrest of cells in the G1 phase.

\section{p44 affects expression of some AR-target genes}

Next, we examined genes, whose expression was altered by the expression of f:NLS-p44 in LNCaP cells. It has been shown that cell-cycle-control genes, such as $p 21$, $C D K 2$, and $C D K 4$ are regulated by the androgensignaling pathway ( $\mathrm{Lu}$ et al. 1997). On the basis of previous observations that $\mathrm{p} 44$ functions as a cofactor for the AR (Hosohata et al. 2003), we first investigated whether f:NLS-p44 expression would alter the expression of these cell-cycle regulators. Northern blot analysis revealed that f:NLS-p44 expression increased p21 expression (200\%) and decreased CDK2 expression (60\%; Fig. 3A, lane 2 vs lane 1). In contrast, f:NLS-p44 expression did not affect $p 27, C D K 4$, and $\beta$-actin expression. Consistent with the northern blot analysis, western blotting showed that the $p 21$-protein levels were increased in the f:NLS-p44-expressing LNCaP cells (Fig. 3A, lane 5 vs lane 4). Given the fact that $p 21$ inhibits cell proliferation by inhibiting cell-cycle progression from $\mathrm{G} 1$ to $\mathrm{S}$ phases and $C D K 2$ promotes this progression, inhibition of LNCaP cell proliferation by expression of f:NLS-p44 may result from the upregulation of $p 21$ gene expression and downregulation of $C D K 2$ gene expression.

We also investigated whether f:NLS-p44 expression would alter the expression of other known AR-target genes by DNA CHIP and real-time PCR (RT-PCR) analyses. The f:NLS-p44 expression dramatically (10 6 -fold by DNA CHIP assay; $6 \cdot 02$-fold by RT-PCR analysis) enhanced $P S A$ gene expression and slightly (1.79-fold by RT-PCR) increased PDEF gene expression (Fig. 3C). In contrast, f:NLS-p44 expression inhibited (2.60-fold by DNA CHIP assay; $2 \cdot 70$-fold by RT-PCR analysis) Maspin gene expression. It has been known that the AR pathway positively regulated expression of the PSA and PDEF genes (Cleutjens et al. 1996, Oettgen et al. 2000, Gao et al. 2005) and negatively regulated expression of the Maspin gene (Zhang et al. 1997). These results imply that p44 may also function as an AR cofactor to modulate the expression of the PSA, PDEF, and Maspin genes. But, f:NLS-p44 expression did not affect expression of the $I G F B P 5$ gene that was positively regulated by the androgen in LNCaP cells (data not shown). Thus, these results indicated that p44 might function as a cofactor to selectively modulate expression of some AR-target genes. The functional role of the p44 in the regulation of the expression of other genes (PDEF and Maspin) in the prostate needs further investigations.

Consistent with published observations (Lu et al. 1997), we observed that the synthetic androgen (R1881) elevated p21 mRNA in LNCaP cells (Fig. 3B). The previous work has identified a functional androgenresponse element located at $-200 \mathrm{bp}$ p21 proximal promoter region (Lu et al. 1999, 2000). The p21 promoter $(-310$ to $+25 \mathrm{bp})$ luciferase reporter was co-transfected with expression vectors for AR, p44, or both into the PC3 cell in the absence or presence of the synthetic androgen (R1881). As shown in Fig. 4A, AR activated the reporter gene by about twofold in the presence of R1881, and the co-expressed p44 showed a further enhancement of this activity. p44 did not influence reporter gene activity in the absence of R1881, indicating that the enhancing effect of p44 on the p21 reporter activity was androgen dependent (Fig. 4A). The CHIP analysis revealed the androgeninduced recruitment of AR onto the p21 promoter (Fig. 4B, lane 3 vs lane 4). Similarly, p44 was also recruited onto the p21 promoter in the presence of the androgen (Fig. 4B, lane 7 vs lane 8 ). These results suggest that, as a transcriptional cofactor, p44 specifically and directly regulates p21 expression in the presence of $\mathrm{AR}$. 


\section{Mice lacking one allele of the p44 gene developed prostatic hyperplasia}

To investigate the role of p44 in living animals, we generated mice carrying the inactivated $p 44$ gene by homologous recombination. ES cell clones with a disrupted $p 44$ locus were used to obtain germline chimeras that, in turn, were used to generate heterozygous F1 mutant 129v//C57BL hybrid mice (Fig. 5A). Crosses between mice heterozygous for the $p 44$ gene led to wild-type $\left(p 44^{+/+} ; n=145\right)$ and heterozygous $\left(p 44^{+/-} ; n=327\right)$ mice, but not homozygous mice, thus indicating that the $p 44$ gene is essential for murine embryogenesis. The $p 44^{-1-}$ embryos died before
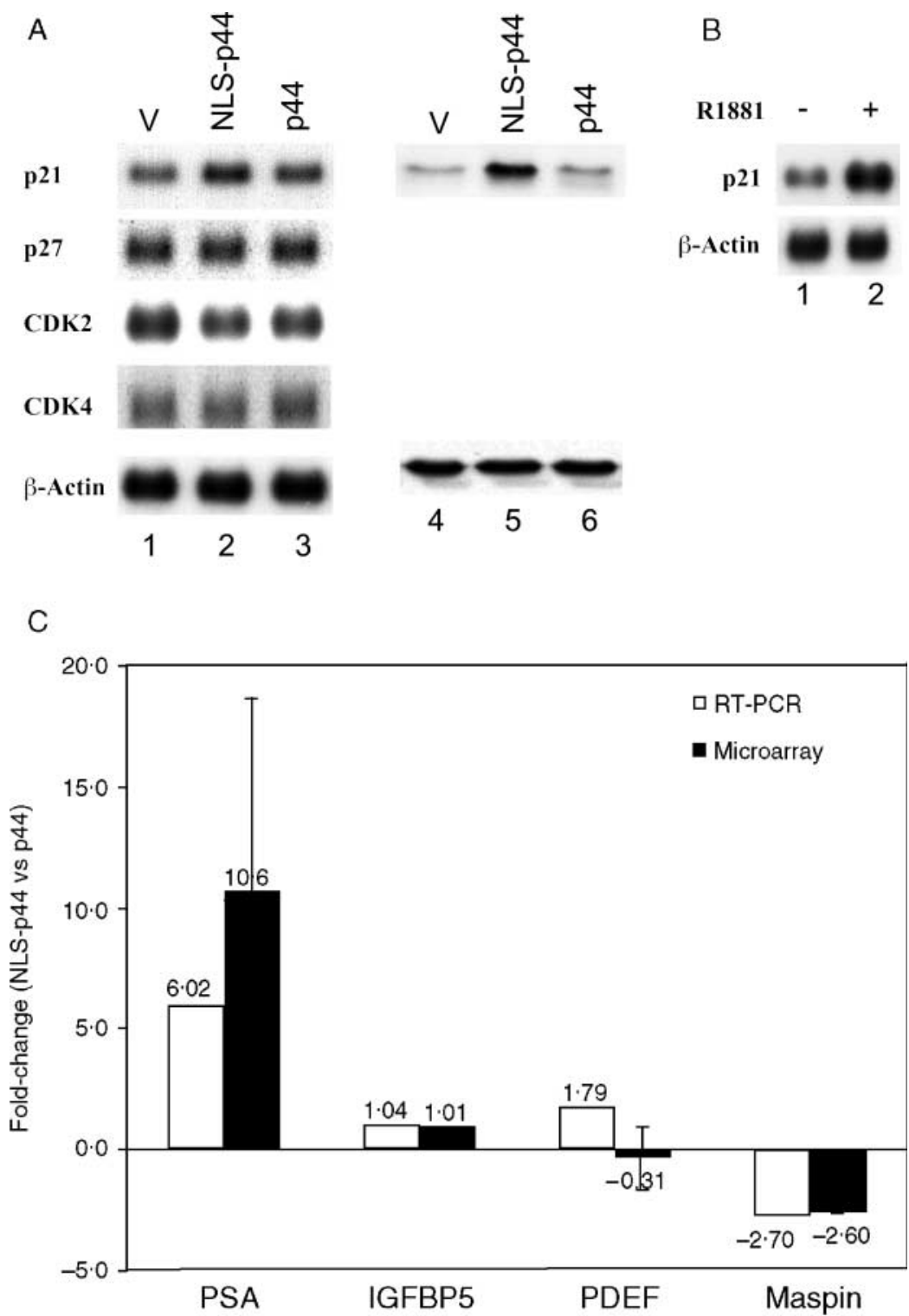

Figure 3 The subcellular translocation of p44 altered AR-target gene expression. (A) Northern blot (lanes 1-3) and western blot (lanes 4-6) analyses of gene expression in the vector (V; lane 1), f:NLS-p44 (lane 2), and f:p44 (lane 3) stably transfected LNCaP cells. (B) Northern blot analysis of p21 expression in LNCaP cells in response to androgen. LNCaP cells were grown in the absence (lane 1) and presence (lane 2) of $10 \mathrm{nM}$ R1881 for 2 days. The mRNAs were isolated, fractionated by electrophoresis, and transferred to a Hybond $\mathrm{N}^{+}$membrane. The membrane was hybridized with $\mathrm{p} 21$ probe (top panel) or $\beta$-actin probe (bottom panel). (C) DNA CHIP and RT-PCR analyses of AR-target gene expression in f:NLS-p44 and f:p44 stably transfected LNCaP cells. 
A

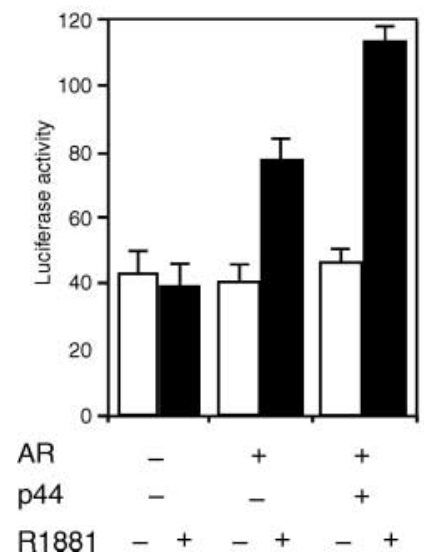

B

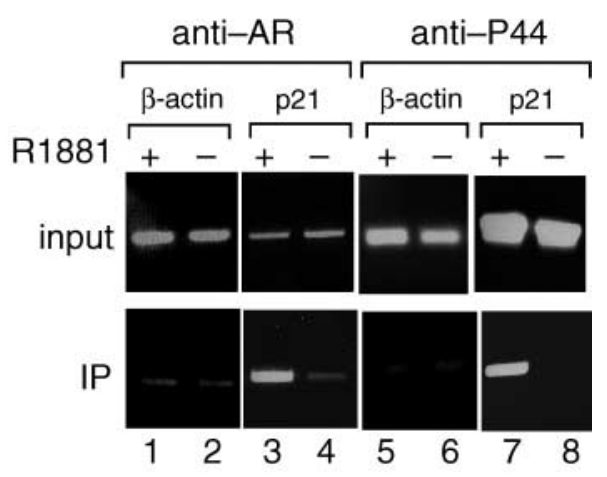

Figure 4 p44 directly targets the p21 gene. (A) p44 affected AR-driven p21 promoter activity. PC3 cells were transfected with the p21-luciferase reporter, pcDNA-AR, and pcDNA-p44 as indicated and the transfected cells were grown in the absence or presence of the androgen and then submitted for the dual-luciferase assay.

(B) Chromatin immunoprecipitation assay to identify p21 as an AR and p44 as a direct target gene. The f:NLS-p44-LNCaP cells were grown in the absence (lanes 2, 4, 6, and 8) and presence (lanes 1, 3, 5, and 7) of $10 \mathrm{nM} \mathrm{R1881.} \mathrm{Immunoprecipitation} \mathrm{was} \mathrm{performed}$ with antigen-purified anti-AR (lanes 1-4) or anti-p44 (lanes 5-8) antibodies. The purified DNA was amplified by a PCR with two specific primers derived from promoter regions of $\beta$-actin (lanes 1, 2, 5, and 6) or p21 (lanes 3, 4, 7, and 8). The same set of PCRs was performed with chromatin DNA used for immunoprecipitation (IP; top panel).

E8.5 day for unknown reasons. The loss of one copy of the $p 44$ gene in $p 44^{+/-}$heterozygous mice was confirmed by Southern blot analysis of tail genomic DNAs (Fig. 5B). The decrease in p44 expression was confirmed by northern blot analysis of prostate mRNAs and western blot analysis of the prostate extracts (Fig. 5C, D). The $p 44^{+/-}$males and females were fertile and generated normal litter sizes.

To determine whether the loss of one allele of the $p 44$ gene affects prostate growth and development, we kept a cohort of $p 44^{+/-}$and wild-type animals (50\% with the C57BL genetic background and 50\% with the 129SvJ genetic background) for long-term observation of the development and growth of the prostate gland. To avoid potential variations due to their genetic background, only mice from the F2 generation were used. At the age of 2 months, 22 males of the F2 $p 44^{+/-}$littermates were killed. Histological analysis revealed multifocal hyperplasia in the dorsal prostate in $16(73 \%)$ of $22 p 44^{+/-}$ male mice. Figure 6 shows a comparison of dorsal lobes from two wild-type mice (A and D) and their four $p 44^{+/-}$(B, C, E, and F) littermates. At this stage, hyperplastic ECs filled many prostate glands (Fig. 6B, C, $\mathrm{E}, \mathrm{F}$, indicated by white arrows). In contrast, none of five male wild-type mice displayed prostate hyperplasia (Fig. 6A, D). Similarly, $12(40 \%)$ of $30 p^{44^{+/}}$mice at the age of 6 months and $5(31 \%)$ of $16 p 44^{+/-}$male mice at the age of 12 months showed hyperplasia in the dorsal prostate. Under higher magnification, prominent nucleoli were observed in the nucleus of hyperplastic ECs of the $p 44^{+/-}$mice at the ages of 2,6 , and 12 months (Fig. 6G-I). In the 2-month-old $p 44^{+/-}$mice, hyperplastic ECs still maintained a parallel alignment along the basal cells, which was absent in the 6-month-old $p 44^{+/-}$mice (Fig. 6G, H). In the 12-month-old $p 44^{+/-}$mice, ECs within the same gland further developed into several small glands, reminiscent of those observed in prostate tumors (Fig. 1C). The small glands were still surrounded by the basement membrane and the fibromuscular layer. However, no prostate tumors developed in $p 44^{+/-}$mice at ages up to 12 months, which represents the oldest mice analyzed to date. No hyperplasia was observed in the ventral part of prostate glands in $p 44^{+/-}$mice (data not shown).

\section{The loss of one allele of the p44 gene changed expression of the AR-target genes in the prostate gland}

Immunohistochemical analyses showed strong AR staining in the nucleus of ECs in the prostate of wild-type mice and $p 44^{+/-}$mouse prostate gland (Fig. 7A, B). Similarly, p44 was detected in the nucleus of ECs in the wild-type and $p 44^{+/-}$mouse prostate gland (Fig. 7C, D). The northern blot analysis indicates that $P D E F$ gene expression decreased in the $p 44^{+/-}$mouse prostate (Fig. 7E, lanes 1,2). In contrast, the CDK2 and Maspin gene expressions increased in the $p 44^{+/-}$mouse 

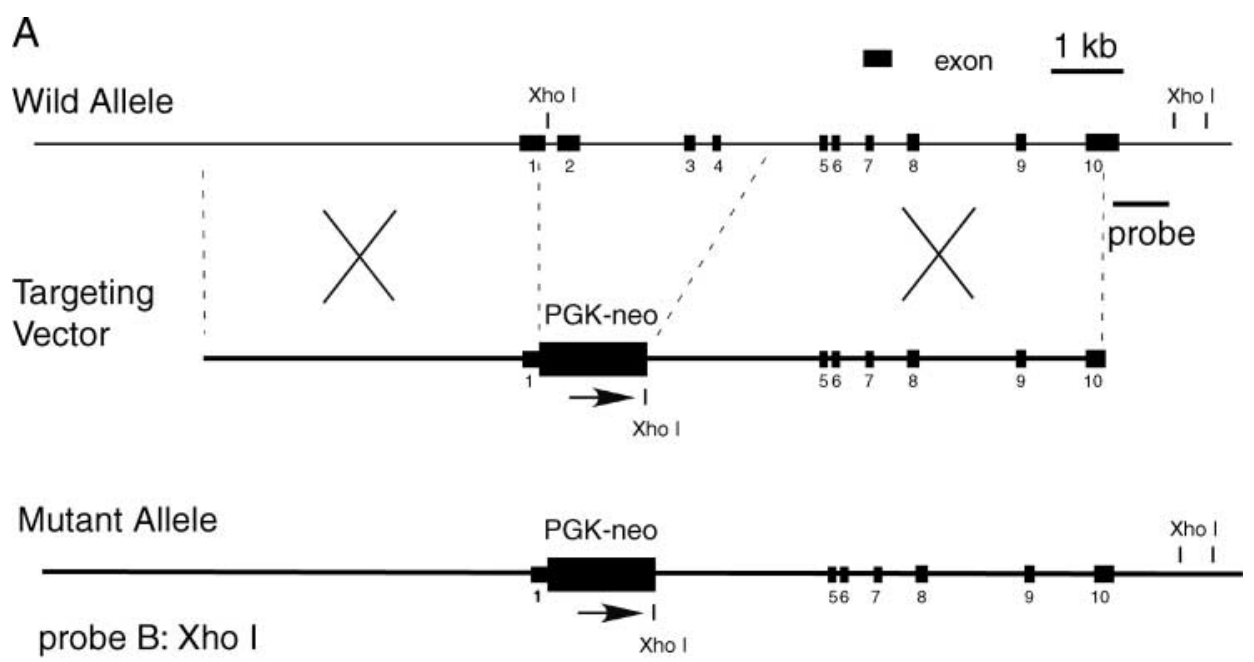

Wild: $8.6 \mathrm{~kb}$

Mutant: $5 \cdot 7 \mathrm{~kb}$

B

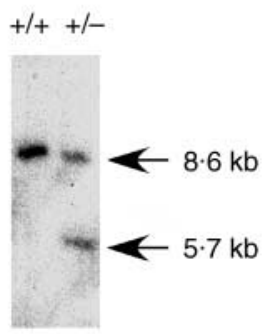

12
C

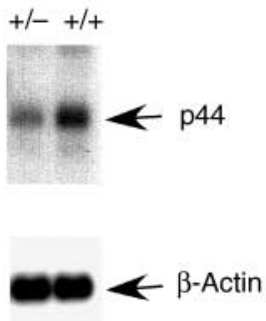

12
$\mathrm{D}$

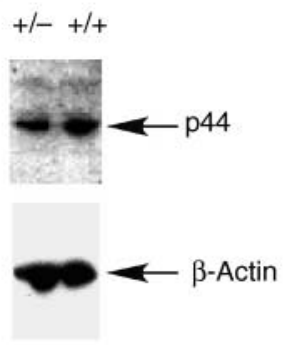

12

Figure 5 Generation of the p44-deficient mice. (A) Diagram of the strategy to generate p44-deficient mice. The wild-type allele of the mouse $p 44$ gene and the predicted mutant allele resulting from homologous recombination are presented. (B) Southern blot analysis of offspring obtained by a heterozygous cross. The wild-type allele $(8.7 \mathrm{~kb})$ and mutant allele $(5.6 \mathrm{~kb})$ are indicated by arrows. (C) Northern blot analysis of p44 and $\beta$-actin mRNAs in prostate gland. The mRNA was isolated from the prostate glands of five wild-type (lane 2) or five $p 44^{+/-}$(lane 1) mice, fractionated by electrophoresis, and transferred to a Hybond $\mathrm{N}^{+}$membrane. The membrane was hybridized with a p44 probe (top panel) or $\beta$-actin probe (bottom panel). (D) Western blot analysis of p44 expression in prostate cells. Protein extracts were prepared from the prostate glands of five wild-type (lane 2) or five $p 44^{+l-}$ (lane 1) mice. Twenty micrograms of protein extracts were fractionated by $12 \%$ SDS-PAGE electrophoresis and transferred to an NC membrane. The membrane was blotted with anti-p44 (top panel) or anti- $\beta$-actin (bottom panel) antibody.

prostate gland (Fig. 7E, lanes 3-6). The more sensitive RT-PCR analysis was performed to investigate the altered expression of AR-target genes in the $p 44^{+/-}$mouse prostate gland (Fig. 7F). The loss of one copy of the p44 gene decreased $M E P, P D E F$, and $N K X 3 \cdot 1$ gene expression by $1 \cdot 25-, 1 \cdot 49-$, and $2 \cdot 0$-fold respectively, and increased $C D K 2$, Maspin, and TGF- $\beta 1$ gene expression by $2 \cdot 11-$, $2 \cdot 25$-, and $2 \cdot 87$-fold respectively. The $N K X 3 \cdot 1$ and $N E P$ genes are positively regulated and the $T G F-\beta 1$ gene is negatively regulated by the AR pathway in the prostate gland (Bieberich et al. 1996, Denmeade et al. 1996, Shen et al. 2000). Thus, p44 modulated the expression of the
AR-target genes, such as the $M E P, N K X 3 \cdot 1, p 21, P D E F$, $P S A, C D K 2$, Maspin, and TGF- $\beta 1$ genes.

\section{Development of prostate hyperplasia in heterozygous p44 mice was dependent on the androgen-signaling pathway}

The androgen-signaling pathway is critical for the development and function of the prostate gland and for prostate tumorigenesis. To assess whether prostate hyperplasia in mice with the loss of one allele of the p44 gene is dependent on the androgen-signaling 

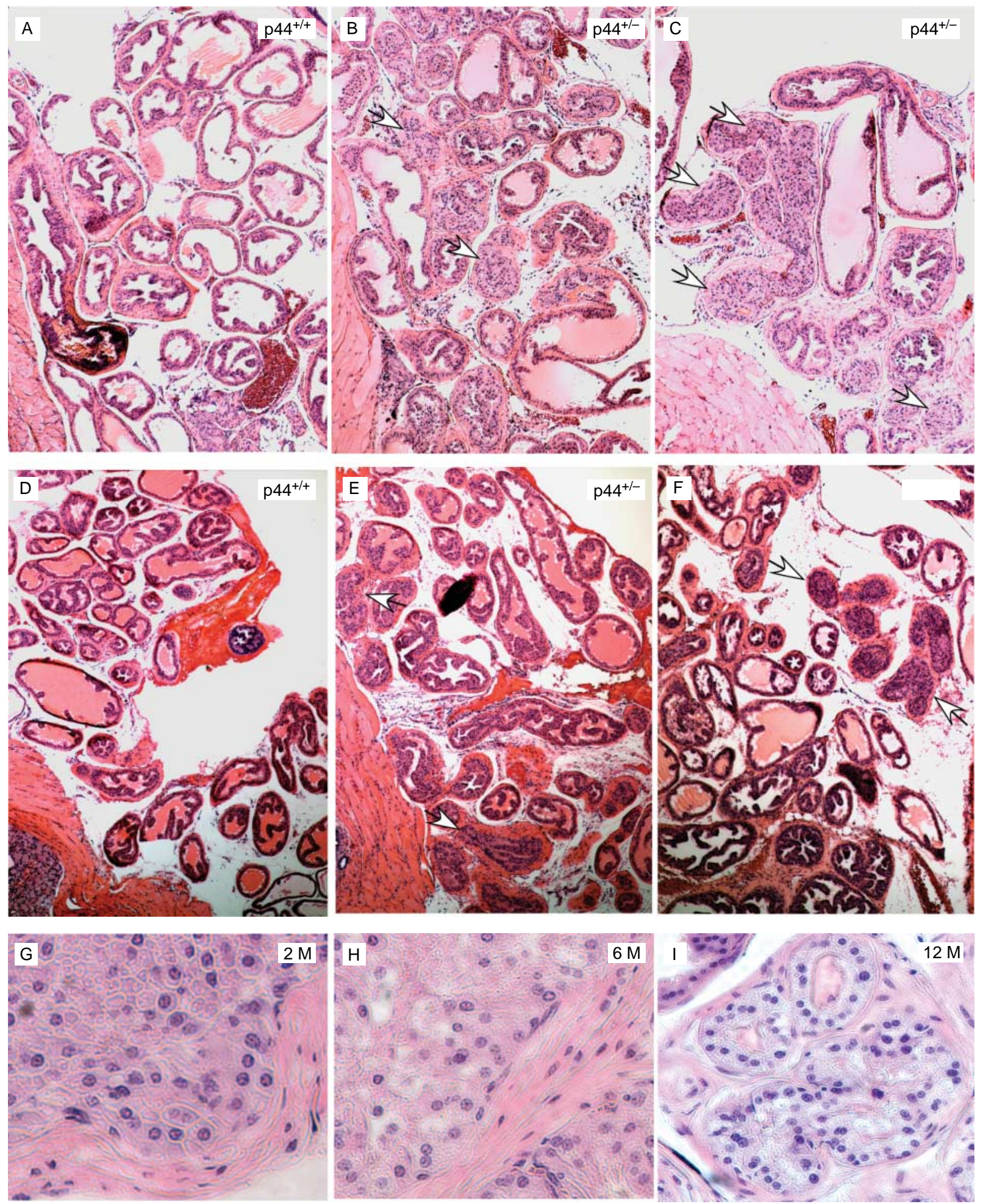

Figure 6 Heterozygous $p 44$ gene deletion leads to spontaneous development of prostate hyperplasia. Hematoxylin and eosin staining of the dorsal prostate cells of two wild-type (A and $D)$ and four $p 44^{+/-}(B, C, E$, and $F)$ mice by 2 months of age. Some hyperplastic lesions are indicated by white arrows. G-I show the hyperplasia regions of the dorsal prostate glands of $p 44^{+i-}$ mice at the ages of 2,6 , and 12 months. Original magnification is $3 \cdot 2 \times$ for $A-F$ and $32 \times$ for $\mathrm{G}-\mathrm{I}$. 

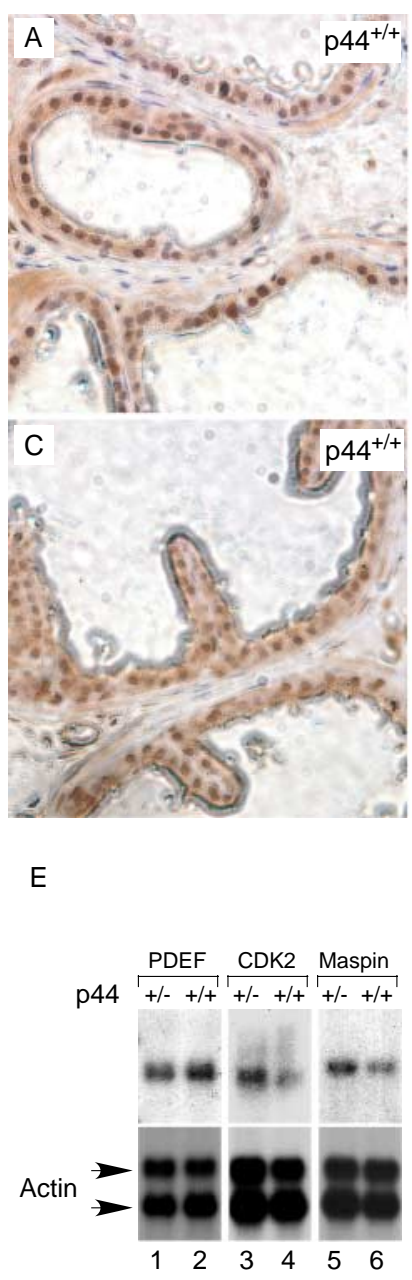

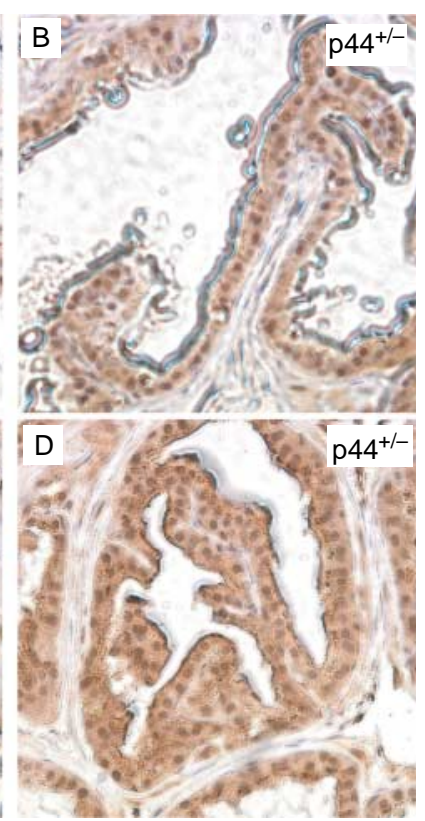

$\mathrm{F}$

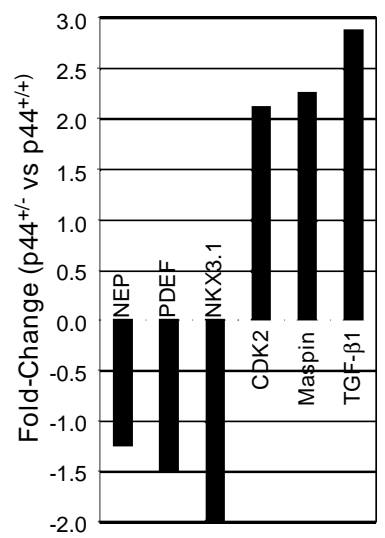

Figure 7 Loss of one allele of the p44 gene leads to the dysregulated expression of some AR-target genes in the mouse prostate. Immunostaining of prostate cells of the wild-type (A and $C$ ) and heterozygous $p 44^{-\gamma+}(B$ and $D)$ mice with the anti-AR (A and $B$ ) or anti-p44 (C and D) antibodies. (E) Northern blot analysis of expression of the AR-target genes in the prostate gland. The mRNAs were isolated from the prostate glands of five wild-type (lanes 2, 4, and 6) or five $p 44^{+}-$(lanes 1, 3, and 5) mice, fractionated by electrophoresis, and transferred to a Hybond $\mathrm{N}^{+}$ membrane. The membrane was hybridized with cDNA probes of PDEF, CDK2, and Maspin (top panel) or $\beta$-actin (bottom panel) genes. (F) RT-PCR analysis of AR-target gene expression in the prostate gland. The total RNAs were isolated from the prostate glands of two wild-type and two $p 44^{+/-}$mice. The RT-PCR analysis was performed with gene-specific primers as indicated.

pathway, we castrated the male mice at 8 weeks of age, 30 days later implanted testosterone for 60 days, killed the mice and dissected the prostate glands for histological analysis. In response to androgen withdrawal, the well-branched prostate glands changed into small non-branched glands (English et al. 1987; Fig. 8A and $\mathrm{B}$ vs Fig. $6 \mathrm{~A}$ and $\mathrm{D}$ ). As a known consequence of castration, the levels of AR protein 


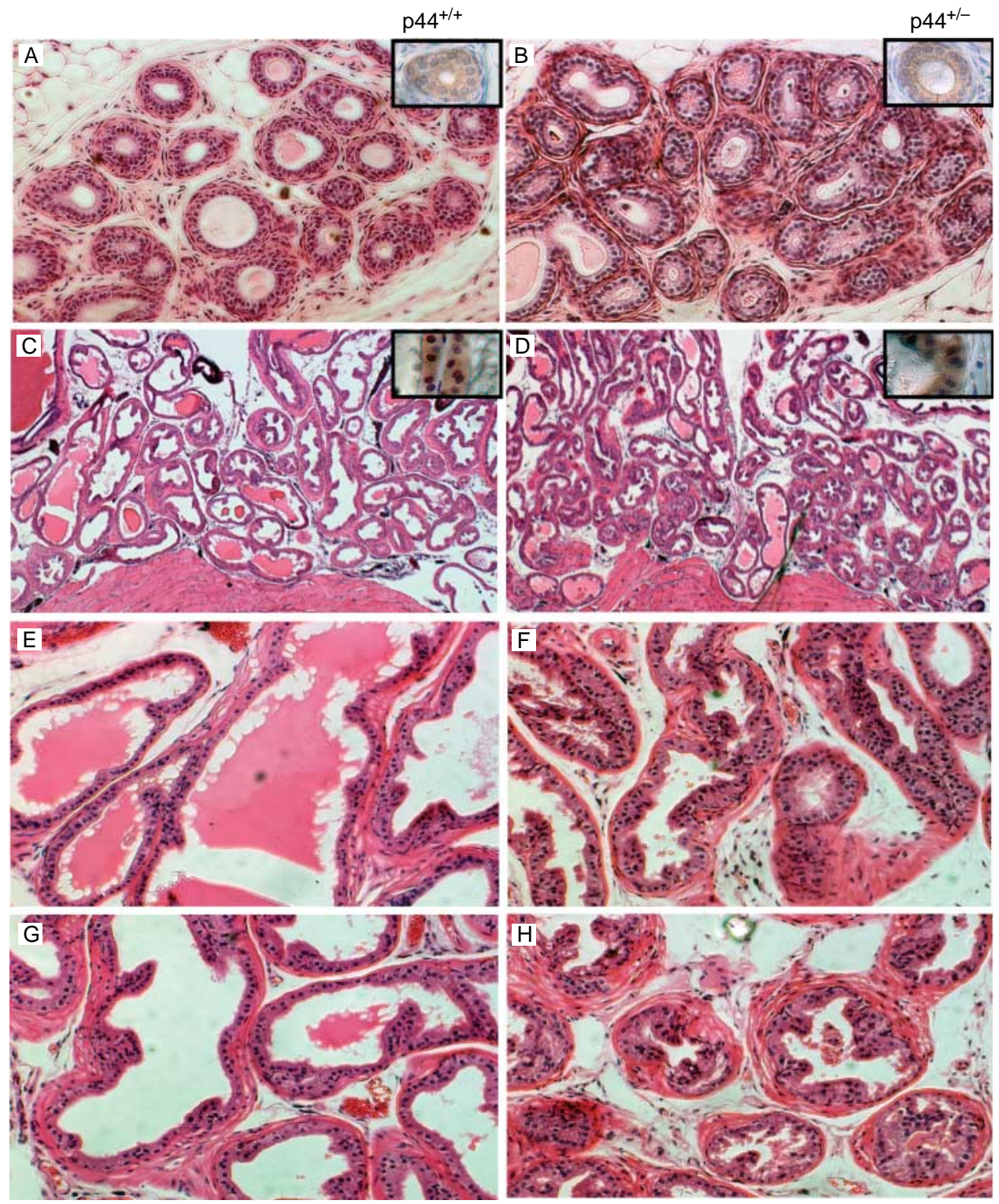

Figure 8 Development of prostate hyperplasia in heterozygous p44 mice is androgen dependent. Hematoxylin and eosin staining of ventral-dorsal prostate ECs of the wild-type (A, C, E, and F) and $p 44^{+1-}$ $(B, D, F$, and $H)$ mice 30 days after castration $(A$ and $B)$ or 60 days after testosterone implantation $(C-H)$. Original magnification is $3 \cdot 2 \times$ for $C$ and $D$ and $16 \times$ for $A, B$, and $E-H$. Inserts: immunostaining of $A R$.

dramatically decreased in the ECs of prostate glands in both wild-type and $p 44^{+/-}$mice (Fig. $8 \mathrm{~A}$ and $\mathrm{B}$, inserts). Prostate hyperplasia was not observed in the wild-type and castrated $p 44^{+/-}$mice (Fig. $8 \mathrm{~A}$ and $\mathrm{B}$ ), implying that the intact androgen pathway is required for the development of prostate hyperplasia in $p 44^{+/-}$ mice. The testosterone implantation restored AR expression in the prostate ECs of wild-type and $p 44^{+/-}$mice (Fig. 8C and D, inserts) and generated the normal morphology of the prostate gland in wild-type mice (English et al. 1987; Fig. 8C, E, and $\mathrm{G})$. Compared with the wild-type prostate gland, the $p 44^{+/-}$prostate gland displayed overgrown ECs, which formed multiple layers after testosterone implantation (Fig. 8D, F, and H). Therefore, these results suggest that the overproliferation of ECs caused by the loss of one allele of the $p 44$ gene is androgen dependent. 


\section{p44 is required for prostate epithelial cell differentiation}

Antibodies to cytoskeletal proteins of the keratin subclasses have been used to study prostate cell differentiation (Schalken \& van Leenders 2003). These studies demonstrated that changes in the levels of differentiation are accompanied by a distinct transition in the expression profile of individual keratins. ECs in the adult prostate could be characterized as basal cells $\left(\mathrm{K}^{+} /\right.$ $\left.\mathrm{K} 18^{-}\right)$, luminal cells $\left(\mathrm{K}^{-} / \mathrm{K} 18^{+}\right)$, and intermediate

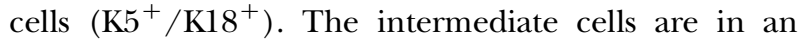
intermediate state of differentiation (Xue et al. 1998); they stem from basal cells and eventually differentiate into luminal cells. Sections of the wild-type and $p 44^{+/-}$ prostate glands were immunohistochemically stained with anti-K5 and anti-K18 antibodies. K18 was positive in all luminal cells (Fig. 9A, a and b, indicated by black arrows) and negative in all basal cells (indicated by white arrows) of wild-type and hyperplastic $p 44^{+/-}$prostate. In contrast, $\mathrm{K} 5$ was expressed in the basal cells of wild-type and hyperplastic $p 44^{+/-}$prostate glands (Fig. 9A, $c$ and $\mathrm{d}$, indicated by white arrows), but not in the luminal cells of the wild-type prostate glands (c). However, K5 was detectable in the hyperplastic ECs of the $p 44^{+/-}$prostate glands (Fig. 9A, d, indicated by black arrows). These results suggest that the hyperplastic ECs in prostate glands result from the loss of one allele of the $p 44$ gene,
A
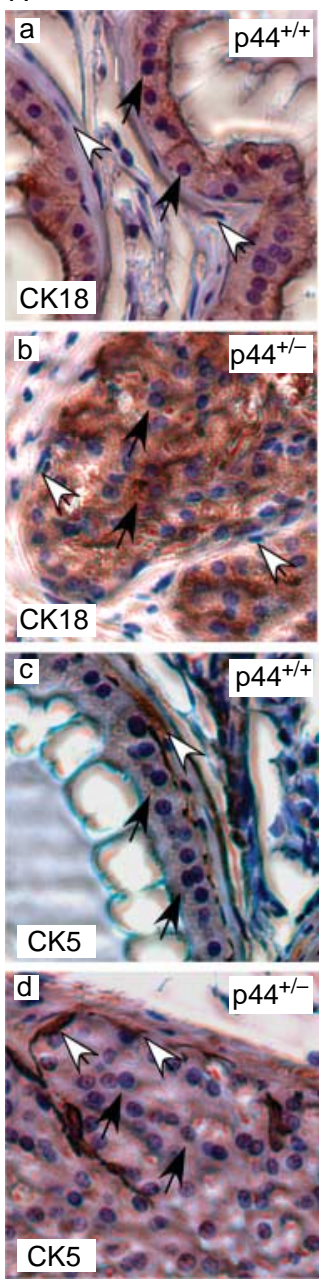

$\mathrm{B}$

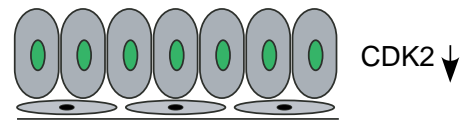

differentiated luminal epithelia

(NORMAL)

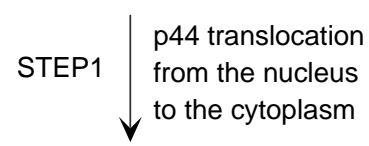

CDK2 $\uparrow$

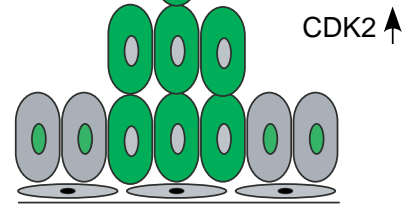

proliferating luminal epithelia

(HYPERPLASIA)
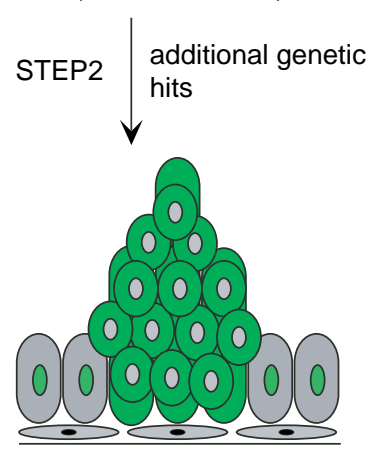

neoplastic luminal epithelia

(CANCER)

Figure $9 \mathrm{p} 44$ is involved in prostate EC differentiation. (A) Immunostaining of prostate ECs of wild-type (a and c) and $p 44^{+/-}(\mathrm{b}$ and d) mice with anti-keratin 18 ( $\mathrm{a}$ and $\mathrm{b})$ and antikeratin 5 ( $c$ and d) antibodies. The basal and luminal cells are indicated by white and black arrows respectively. Original magnification is $32 \times$. (B) A model depicting the effects of p44 translocation on tumor initiation. Green represents the p44 protein. 
are intermediate cells $\left(\mathrm{K}^{+} / \mathrm{K} 18^{+}\right)$, and not fully differentiated.

\section{Discussion}

The androgen pathway plays multiple roles in the prostate gland and in prostate tumorigenesis, although the mechanisms underlying these roles remain obscure. We report here that the p44 translocation from the nucleus to the cytoplasm is strongly associated with prostate tumorigenesis. The major consequence of the nuclear p44 translocation was to inhibit the proliferation of ECs apparently by upregulating p21 expression and downregulating CDK2 expression. The disruption of the p44 function in the nucleus could account for the haploinsufficient hyperplasia observed in the p44 knockout mice and the proliferation of ECs in the human prostate gland. Our findings revealed that the AR cofactor (p44) plays a critical role in the control of EC growth and differentiation.

\section{p44 modulates AR-driven gene expression}

p44 is identified by its physical association with AR in prostate cancer cells. p44 was recruited onto the PSA promoter in vivo in the presence of androgen, and it enhanced AR-driven gene expression both in vitro and in vivo (Hosohata et al. 2003). These observations suggest that p44 performs its functions through modulating AR-driven gene expression. Consistent with this conclusion, the forced nuclear localization of p44 selectively upregulates the expression of the $p 21$ gene, which has been shown to be directly targeted by the androgen-signaling pathway ( $\mathrm{Lu}$ et al. 1999, 2000). The CHIP analysis shows that p44 and AR were recruited onto the endogenous $p 21$ gene in the presence of androgen. The transient transfection assay demonstrated that $\mathrm{p} 44$ and AR together enhanced p21 promoter activity. Thus, these observations define the positive cofactor function of $\mathrm{p} 44$ for AR on the $p 21$ gene. In contrast, the forced nuclear localization of $\mathrm{p} 44$ downregulated the expression of the CDK2 gene, indicating that p44 functions as a negative cofactor for the AR on this gene. Consistent with this hypothesis, we found a negative AR-responsive element in the $C D K 2$ gene (data not shown). The DNA CHIP and RT-PCR analyses revealed that the forced nuclear localization of p44 also enhanced the expression of the PSA and PDEF genes and decreased the expression of the Maspin gene. Similarly, the northern blot and RT-PCR analyses revealed that the expression of the NEP, PDEF, $N K X 3 \cdot 1, C D K 2$, Maspin, and TGF- $\beta 1$ genes in the mouse prostate gland was affected by the loss of one allele of the $p 44$ gene. Thus, our results indicated that p44 may function as a cofactor to selectively modulate expression of some AR-target genes. On the basis of the lethal phenotype of the $p 44$ knockout mice, we anticipated that $\mathrm{p} 44$ is also required for the expression of the other non-AR target genes, which are essential for mouse embryonic development. Although p44 was expressed in various tissues (Hosohata et al. 2003), we observed no obvious pathologic defect in other tissues or organs in the $p 44^{+/-}$mice.

\section{The nuclear p44 inhibits cell proliferation through G1 arrest}

Cell proliferation is normally a strictly controlled process that depends on the balance among cell growth, cell division, and apoptosis. Many tumor suppressor genes, including $p 53$ and $p R b$, inhibit cell growth by modulating cell-cycle progression (Sherr \& McCormick 2002). It has been shown that p53 directly targets the $p 21$ gene to arrest the cell cycle at G1 and $\mathrm{pRb}$ regulates E2F activity to affect the G1-S-phase transition during cell-cycle progression. We observed no significant differences in apoptosis rates between the LNCaP cell lines with nuclear p44 expression and those without. Instead, p44 nuclear expression inhibited the proliferation rates of LNCaP cells by G1 arrest. During the G1 phase, cells must store enough energy for the next cell cycle and concurrently check external and internal signaling events to decide whether to commit to the next cell cycle (Niklinska et al. 2001). In our experiments, most cells expressing NLS-p44 became arrested in the G1 phase. Possible molecular mechanisms by which the nuclear p44 inhibited cell growth and G1 arrest are suggested by modulating the expression of the key cell-cycle regulators, p21 and CDK2. CDK2 plays a key role in regulating G1-S transition, and p21 is a potent inhibitor of this transition (Shackney \& Shankey 1999). Consistent with this conclusion, the loss of one p44 allele increased CDK2 expression in the prostate ECs.

\section{The role of $\mathrm{p} 44$ in prostate tumorigenesis}

The androgen-signaling pathway plays a critical role in the growth and maintenance of the prostate gland and is a predominant target for prostate cancer therapies (Santos et al. 2004). It has been suggested that dysregulation of this signaling pathway by loss of the NKX3 1 allele contributes to prostate hyperplasia in mice (Magee et al. 2003). The p44 translocation into the cytoplasm was strongly associated with the proliferation of prostatic ECs and the forced nuclear localization of p44 seriously retarded the proliferation of prostate cancer cells, indicating that p44 functions in the nucleus as a negative factor for cell growth. Consistent 
with these observations, mice lacking only a single allele of p44 develop prostatic hyperplasia as young adults. The p44-mediated growth arrest appeared to be androgen dependent on the basis of the following observations. First, the modulation of $p 21$ and CDK2 gene expression by p44 was androgen dependent. Secondly, the downregulation of p44 function by a dominant-negative p44 mutant enhanced the androgen-dependent (LNCaP) cell growth, but not the androgen-independent (PC3) cell growth (data not shown). Thirdly, the prostate hyperplasia that resulted from the loss of one allele of the $p 44$ gene was dependent on the intact androgen pathway.

Haploinsufficiency has been demonstrated at many tumor-suppressor loci (Magee et al. 2003). Mice lacking one of these tumor suppressors develop cancerous or precancerous lesions despite the expression of remaining wild-type allele. Similarly, mice lacking only a single allele of p44 develop prostatic hyperplasia. Prostate tumorigenesis is a multistep process involving both genetic alterations (activation of oncogenes and inactivation of tumor suppressor genes) of the ECs and perturbation of stromal-epithelial interactions (Wong et al. 2003). The p44 translocation is a very early event leading to the proliferation of prostatic ECs (dividing one layer into two and more layers). These observations documented a novel mechanism controlling prostatic EC proliferation (Fig. 9B). The nuclear p44 establishes or maintains prostatic ECs in a growth-arrest (differentiation) state (G1/G0 cell-cycle stage) through the regulation of expression of cell-cycle regulators, such as p21 and CDK2. Conversely, the p44 cytoplasm localization or decreased p44 levels in the nucleus by the loss of one allele of the $p 44$ gene would relieve this growth arrest and result in EC proliferation. The proliferating ECs would then afford the opportunity for further genetic mutations to occur, thereby facilitating the progression to prostrate cancer. One notable feature of the hyperplasia observed in $p 44^{+/-}$mice is its rapid and spontaneous onset. This raises the possibility that the loss of one copy of the $p 44$ allele is sufficient to induce epithelial proliferation in the mouse prostate gland in the absence of any secondary changes.

The translocation of proteins play important regulatory roles in their functions (Yu \& Berkel 1999). It has been demonstrated that many transcriptional factors, such as p53 (Liang \& Clarke 2001) and FKHRL1 (Tzivion \& Avruch 2002) are regulated by nuclear or cytoplasm localization. We observed that the translocation of p44 from the nucleus into the cytoplasm was correlated with proliferation of prostate ECs. Analysis of various deletions of $\mathrm{p} 44$ fused to EGFP revealed that there are two nuclear exclusion signal (NES) sequences in the $\mathrm{p} 44$ protein (data not shown). Sequence analysis indicated that the N-terminal NES of p44 is similar to that found in the Smad proteins (Xiao et al. 2003) and the C-terminal does not have a known parallel. There are two NES signals in the p44 sequence, which suggest a novel mechanism controlling the p44 cytoplasm localization. Consistent with this hypothesis, the chemical leptomycin B, which inhibits the nuclear exclusion of proteins that have leucine-rich NES by blocking the translocation cargo molecule CRM1 (Yu \& Berkel 1999), did not affect the cytoplasm localization of p44 in LNCaP cells (data not shown). Presently, we are investigating the signaling that controls the p44 subcellular localization.

Although the molecular events that lead to the proliferation of prostate ECs remain enigmatic, our findings suggest a novel mechanism that initiates the proliferation of prostatic ECs through control of the p44 subcellular colonization. These results are important because they are the first to show that $\mathrm{p} 44$, as an AR cofactor, is involved in controlling the differentiation and proliferation of prostate ECs. In addition, p44deficient mice may provide an animal model suitable for studying the molecular events underlying the predisposition to prostate hyperplasia and initiation of prostate cancer.

\section{Acknowledgements}

We thank Ms Sandra L Young for the critical editorial review, Drs Keiko Hosohata, Hua Wang, and Mitsuhiro Ito for help with construction of the mouse $p 44$ gene target vector, and Dr Jan Parker-Thornburg in the Genetically Engineered Mouse Facility at MD Anderson Cancer Center for generation of the $p 44$ gene knockout mouse. This work was supported in part by a grant (1R01 DK065156 01) to Z W from the National Institute of Diabetes and Digestive and Kidney Diseases, National Institutes of Health, by a Cancer Center Support Core grant (CA16672) to The University of Texas, MD Anderson Cancer Center from the National Cancer Institute, National Institutes of Health, and by a VA Merit Review Grant to P L. The authors declare that there is no conflict of interest that would prejudice the impartiality of this scientific work.

\section{References}

Bieberich CJ, Fujita K, He WW \& Jay G 1996 Prostate-specific and androgen-dependent expression of a novel homeobox gene. Journal of Biological Chemistry 271 31779-31782.

Brinkmann AO, Blok LJ, de Ruiter PE, Doesburg P, Steketee K, Berrevoets CA \& Trapman J 1999 Mechanisms of androgen receptor activation and function. Journal of Steroid Biochemistry and Molecular Biology 69 307-313.

Buchanan G, Irvine RA, Coetzee GA \& Tilley WD 2001 Contribution of the androgen receptor to prostate cancer predisposition and progression. Cancer Metastasis Reviews 20 207-223. 
Cleutjens KB, van Eekelen CC, van der Korput HA, Brinkmann AO \& Trapman J 1996 Two androgen response regions cooperate in steroid hormone regulated activity of the prostate-specific antigen promoter. Journal of Biological Chemistry 271 6379-6388.

Culig Z, Comuzzi B, Steiner H, Bartsch G \& Hobisch A 2004 Expression and function of androgen receptor coactivators in prostate cancer. Journal of Steroid Biochemistry and Molecular Biology 92 265-271.

Dehm SM \& Tindall DJ 2005 Regulation of androgen receptor signaling in prostate cancer. Expert Review of Anticancer Therapy 5 63-74.

Denmeade SR, Lin XS \& Isaacs JT 1996 Role of programmed (apoptotic) cell death during the progression and therapy for prostate cancer. Prostate 28 251-265.

English HF, Santen RJ \& Isaacs JT 1987 Response of glandular versus basal rat ventral prostatic epithelial cells to androgen withdrawal and replacement. Prostate 11 229-242.

Friesen WJ, Paushkin S, Wyce A, Massenet S, Pesiridis GS, Van Duyne G, Rappsilber J, Mann M \& Dreyfuss G 2001 The methylosome, a 20 S complex containing JBP1 and pICln, produces dimethylargininemodified Sm proteins. Molecular and Cellular Biology 21 8289-8300.

Friesen WJ, Wyce A, Paushkin S, Abel L, Rappsilber J, Mann M \& Dreyfuss G 2002 A novel WD repeat protein component of the methylosome binds Sm proteins. Journal of Biological Chemistry 277 8243-8247.

Gao S, Lee P, Wang H, Gerald W, Adler M, Zhang L, Wang YF \& Wang Z 2005 The androgen receptor directly targets the cellular Fas/FasL-associated death domain protein-like inhibitory protein gene to promote the androgen-independent growth of prostate cancer cells. Journal of Molecular Endocrinology 19 1792-1802.

Gelmann EP 2002 Molecular biology of the androgen receptor. Journal of Clinical Oncology 20 3001-3015.

He B \& Wilson EM 2002 The NH(2)-terminal and carboxyl-terminal interaction in the human androgen receptor. Molecular Genetics and Metabolism 75 293-298.

Heinlein CA \& Chang C 2002 Androgen receptor (AR) coregulators: an overview. Endocrine Reviews 23 175-200.

Hosohata K, Li P, Hosohata Y, Qin J, Roeder RG \& Wang Z 2003 Purification and identification of a novel complex which is involved in androgen receptor-dependent transcription. Molecular and Cellular Biology 23 7019-7029.

Huang H \& Tindall DJ 2002 The role of the androgen receptor in prostate cancer. Critical Reviews in Eukaryotic Gene Expression 12 193-207.

Janne OA, Moilanen AM, Poukka H, Rouleau N, Karvonen U, Kotaja N, Hakli M \& Palvimo JJ 2000 Androgen-receptor-interacting nuclear proteins. Biochemical Society Transactions 28 401-405.

Jans DA, Xiao CY \& Lam MH 2000 Nuclear targeting signal recognition: a key control point in nuclear transport? Bioessays 22 $532-544$.

Jenster G 1999 The role of the androgen receptor in the development and progression of prostate cancer. Seminars in Oncology 26 407-421.

Kokontis JM \& Liao S 1999 Molecular action of androgen in the normal and neoplastic prostate. Vitamins and Hormone 55 219-307.

Lee C, Sutkowski DM, Sensibar JA, Zelner D, Kim I, Amsel I, Shaw N, Prins GS \& Kozlowski JM 1995 Regulation of proliferation and production of prostate-specific antigen in androgen-sensitive prostatic cancer cells, LNCaP, by dihydrotestosterone. Endocrinology 136 796-803.

Li P, Yu X, Ge K, Melamed J, Roeder RG \& Wang Z 2002 Heterogeneous expression and functions of androgen receptor co-factors in primary prostate cancer. American Journal of Pathology 161 1467-1474.

Liang SH \& Clarke MF 2001 Regulation of p53 localization. European Journal of Biochemistry 268 2779-2783.

Lindzey J, Kumar MV, Grossman M, Young C \& Tindall DJ 1994 Molecular mechanisms of androgen action. Vitamins and Hormones 49 383-432.

Lu S, Tsai SY \& Tsai MJ 1997 Regulation of androgen-dependent prostatic cancer cell growth: androgen regulation of CDK2, CDK4, and CKI p16 genes. Cancer Research 57 4511-4516.
Lu S, Liu M, Epner DE, Tsai SY \& Tsai MJ 1999 Androgen regulation of the cyclin-dependent kinase inhibitor p21 gene through an androgen response element in the proximal promoter. Journal of Molecular Endocrinology 13 376-384.

Lu S, Jenster G \& Epner DE 2000 Androgen induction of cyclindependent kinase inhibitor p21 gene: role of androgen receptor and transcription factor Spl complex. Journal of Molecular Endocrinology 14 753-760.

Magee JA, Abdulkadir SA \& Milbrandt J 2003 Haploinsufficiency at the Nkx3.1 locus. A paradigm for stochastic, dosage-sensitive gene regulation during tumor initiation. Cancer Cell 3 273-283.

Meister G \& Fischer U 2002 Assisted RNP assembly: SMN and PRMT5 complexes cooperate in the formation of spliceosomal UsnRNPs. EMBO Journal 21 5853-5863.

Mirosevich J, Bentel JM, Zeps N, Redmond SL, D'Antuono MF \& Dawkins HJ 1999 Androgen receptor expression of proliferating basal and luminal cells in adult murine ventral prostate. Journal of Endocrinology 162 341-350.

Nelson PS, Han D, Rochon Y, Corthals GL, Lin B, Monson A, Nguyen V, Franza BR, Plymate SR, Aebersold R et al. 2000 Comprehensive analyses of prostate gene expression: convergence of expressed sequence tag databases, transcript profiling and proteomics. Electrophoresis 21 1823-1831.

Nessler-Menardi C, Jotova I, Culig Z, Eder IE, Putz T, Bartsch G \& Klocker H 2000 Expression of androgen receptor coregulatory proteins in prostate cancer and stromal-cell culture models. Prostate 45 124-131.

Niklinska W, Laudanski J \& Niklinski J 2001 G1 phase of the cell cycle control and lung cancer: biological and clinical implications. Minireview. Neoplasma 48 157-163.

Oettgen P, Finger E, Sun Z, Akbarali Y, Thamrongsak U, Boltax J, Grall F, Dube A, Weiss A, Brown L et al. 2000 PDEF, a novel prostate epithelium-specific ets transcription factor, interacts with the androgen receptor and activates prostate-specific antigen gene expression. Journal of Biological Chemistry 275 1216-1225.

Santos AF, Huang H \& Tindall DJ 2004 The androgen receptor: a potential target for therapy of prostate cancer. Steroids 69 79-85.

Schalken JA \& van Leenders G 2003 Cellular and molecular biology of the prostate: stem cell biology. Urology 62 11-20.

Shackney SE \& Shankey TV 1999 Cell cycle models for molecular biology and molecular oncology: exploring new dimensions. Cytometry 35 97-116.

Shen R, Sumitomo M, Dai J, Hardy DO, Navarro D, Usmani B, Papandreou CN, Hersh LB, Shipp MA, Freedman LP et al. 2000 Identification and characterization of two androgen response regions in the human neutral endopeptidase gene. Molecular and Cellular Endocrinology 170 131-142.

Sherr CJ \& McCormick F 2002 The RB and p53 pathways in cancer. Cancer Cell 2 103-112.

Tilley WD, Wilson CM, Marcelli M \& McPhaul MJ 1990 Androgen receptor gene expression in human prostate carcinoma cell lines. Cancer Research $\mathbf{5 0}$ 5382-5386.

Tzivion G \& Avruch J 2002 14-3-3 proteins: active cofactors in cellular regulation by serine/threonine phosphorylation. Journal of Biological Chemistry 277 3061-3064.

Whitacre DC, Chauhan S, Davis T, Gordon D, Cress AE \& Miesfeld RL 2002 Androgen induction of in vitro prostate cell differentiation. Cell Growth and Differentiation 13 1-11.

Wong YC, Wang XH \& Ling MT 2003 Prostate development and carcinogenesis. International Review of Cytology 227 65-130.

Xiao Z, Brownawell AM, Macara IG \& Lodish HF 2003 A novel nuclear export signal in Smad1 is essential for its signaling activity. Journal of Biological Chemistry 278 34245-34252.

Xu LL, Su YP, Labiche R, Segawa T, Shanmugam N, McLeod DG, Moul JW \& Srivastava S 2001 Quantitative expression profile of androgen-regulated genes in prostate cancer cells and identification of prostate-specific genes. International Journal of Cancer 92 322-328. 
Xue Y, Smedts F, Debruyne FM, de la Rosette JJ \& Schalken JA 1998 Identification of intermediate cell types by keratin expression in the developing human prostate. Prostate 34 292-301.

Yu H \& Berkel H 1999 Prostate-specific antigen (PSA) in women. Journal of the Louisiana State Medical Society 151 209-213.

Yu X, Li P, Roeder RG \& Wang Z 2001 Inhibition of androgen receptormediated transcription by amino-terminal enhancer of split. Molecular and Cellular Biology 21 4614-4625.

Yuan S, Trachtenberg J, Mills GB, Brown TJ, Xu F \& Keating A 1993 Androgen-induced inhibition of cell proliferation in an androgen-insensitive prostate cancer cell line (PC-3) transfected with a human androgen receptor complementary DNA. Cancer Research $\mathbf{5 3}$ 1304-1311.

Zhang M, Magit D \& Sager R 1997 Expression of maspin in prostate cells is regulated by a positive ets element and a negative hormonal responsive element site recognized by androgen receptor. PNAS 94 5673-5678.

Received in final form 5 May 2006

Accepted 30 May 2006

Made available online as an Accepted Preprint 20 June 2006 